\title{
Sulugöl (Tokat-Niksar) Çevresi Rekreasyon Alanına Yönelik Öneri Peyzaj Tasarımı
}

\author{
Nurhan KOÇAN ${ }^{\&}$, Gizem CENGIZ GÖKÇE2 2 \\ 1,2Bartın Üniversitesi, Mühendislik, Mimarlık ve Tasarım Fakültesi, Peyzaj Mimarlığı Bölümü, Bartın \\ ${ }^{1}$ https://orcid.org/0000-0001-9433-7007, ${ }^{2}$ https://orcid.org/0000-0001-9888-8623 \\ 凹: nkocan@bartin.edu.tr
}

\section{ÖZET}

Bu çalışmada Tokat ili Niksar ilçesinde bulunan Sulugöl ve çevresi çalışma alanı olarak ele alınmıştır. Çalışmada, kentsel alanlar ve yakın çevresinde yer alan su kaynaklarının kent ekolojisine sağladığ katkıların artırılması ile doğal ve kültürel özelliklerinin korunmasına yönelik bir peyzaj tasarım önerisi geliştirilmiştir. Çalışmanın amacı, alanın mevcut potansiyelini geliştirirken koruma-kullanma dengesinin kurulmasıdır. Çalışmada 1/1000 ölçekli imar planı üzerinde proje alanı tanımlanmış, yerinde gözlem çalışmaları ve Google Earth'ten alınan görüntüler yardımıyla alanın mevcut durumu tanımlanmıştır. Arazi çalışmaları sırasında, belediye yetkilileri ve yerel halk ile görüşmeler yapılarak ihtiyaç ve beklentiler belirlenmiş̧tir. Elde edilen veriler ışığında alan potansiyeli değerlendirilmiştir. Çalışmada peyzaj tasarımının temel aşamaları olan sorun tanımlama, sörvey, leke, avan ve kesin peyzaj tasarım projesinin oluşturulması aşamaları yapılmıştır. Çalışmada peyzaj tasarımının oluşturulması, projelerin çizimi ve görselleştirmesinde AutoCad 2017, Photoshop CS5, Sketch Up ve Lumion yazılımları kullanılmıştır. Projenin sonuçları bitkisel tasarım projesi, yapısal uygulama projesi ve detaylar şeklinde sunulmuştur.
\end{abstract}

Araştırma Makalesi

Makale Tarihçesi
Geliş Tarihi $\quad: 23.01 .2020$
Kabul Tarihi

Anahtar Kelimeler

Su kıyısı peyzaj tasarımı

Peyzaj tasarım süreci

Rekreasyon alanı,

Niksar (Tokat)

The Impact of Natural Water on Design: Landscape Design Proposal for Sulugöl (Tokat-Niksar) Recreation Area

\begin{abstract}
In this study, Sulugöl located in Niksar district of Tokat province was chosen as the study area. In this study, a landscape design proposal was developed in order to increase the contribution of water resources to urban ecology and to protect its natural and cultural characteristics. The aim of the study was to establish the balance of protection and use while developing the existing potential of the area. In the study, the project area was defined on a 1/1000 scale development plan and the current status of the area was defined with the help of on-site observations and images taken from Google Earth. During the area studies, the needs and expectations were determined by interviews with the municipal authorities and local people. The area potential was evaluated within the data obtained. In this study, AutoCad 2017, Photoshop CS5, Sketch Up and Lumion software were used for the creation of landscape design, drawing and visualization of projects. The results of the study were presented in the form of plant design project, structural application project.
\end{abstract}

\section{Research Article}

$\begin{array}{ll}\text { Article History } & \\ \text { Received } & : 23.01 .2020 \\ \text { Accepted } & : 04.07 .2020\end{array}$

Keywords
Water resources landscape design
Landscape design process
Recreation area
Niksar (Tokat)

Atıf İçin: Koçan N, Cengiz Gökçe G 2021. Sulugöl (Tokat-Niksar) Çevresi Rekreasyon Alanına Yönelik Öneri Peyzaj Tasarımı. KSÜ Tarım ve Doğa Dergisi 24 (1): 90-98. https://doi.org/10.18016/ksutarimdoga.vi.679180.

To Cite: Koçan N, Cengiz Gökçe G 2021. The Impact of Natural Water on Design: Landscape Design Proposal for Sulugöl (Tokat-Niksar) Recreation Area. KSU J. Agric Nat 24 (1): 90-98. https://doi.org/10.18016/ksutarimdoga.vi.679180.

\section{GİRIŞ}

$\mathrm{Su}$ algilanabilir fiziki çevre olan peyzaj kavramının temel bileşeni ve yeşil alanların ana ögesidir. İnsanoğlu, suyu temel besin olarak görmesi dışında birçok alanda kullanmıştır. Suyla su kanalları, suyolları ve göletler yapmış ve tüm rekreasyonel faaliyetlerinde suyu bir obje olarak algılamıştır. Su, peyzaj için hem yaşam hem de tasarım aracıdır. Estetik ve işlevsel anlamlar taşır, göze ve kulağa hitap 
eder (Şahin, 2013). Su, peyzaj tasarımında kullanılabilecek en renkli ve heyecan verici unsurlardan biridir (Burmill et al., 1999; Reesand May, 2002).

$\mathrm{Su}$ yüzeyleri; peyzaj mimarlığında rekreasyonel ve fonksiyonel olarak önemli işlevlere sahip kaynaklardır. Çeşitli biçim ve uzunluklarda olabilen su kıyıları, su ve su sayesinde gelişen yeşil alan ile kente ekolojik katkı sağladıkları gibi kent halkına da sosyalleşme ortamı yaratarak yaşam kalitesini artırırlar. Peyzaj mimarlığı meslek disiplininin temel amaçlarının başında; doğal kaynakların "kapasitelerinin üzerinde ve ekolojik dengeleri bozacak ölçüde kullanılmasını önleyerek kaynakların devamlılığını ve verimliliğini muhafaza altına almak, insan aktivitelerini ekolojik bir çerçeveye oturtmak" gelmektedir (Güney ve Hepcan, 1994). Bu da ekolojik yaklaşımın esas alındığı peyzaj planlama çalışmalarının yürütülmesine bağlıdır.

$\mathrm{Su}$, terapi özelliğiyle birlikte insanları rahatlatıcıdır ve stresten uzaklaştırma etkisine sahiptir. Suyun esnekliği dikkat çeker ve merak uyandırır. Açık alanlardaki su elementi, peyzaj mimarları, çevre tasarımcıları, psikologlar, sosyologlar ve toplum için estetik değeri, duyusal teşviki, sosyal işlevi ve psikolojik faydaları nedeniyle yüksek bir değere sahiptir (Huang, 1998).

Kentsel peyzaj planlamanın ürünlerinden biri olarak yeşil alanlar, kentsel mekanlardaki su sürecini yönlendirmede önemli mekanlardır (Çorbacı ve ark., 2011). İnsanların bedensel ve ruhsal olarak sağlıklı bir şekilde yaşayabilmeleri için kentsel ve kırsal rekreasyon alanları tasarlamak; çeşitli nedenlerle tahrip olmuş alanların onararak bu alanları rekreasyon aktiviteleri için uygun hale getirmek peyzaj mimarlığı çalışmaları arasındadır (Güney ve Hepcan, 1994). Kent çevrelerinde bulunan göl, kıyı ve orman ekosistemleri diğer ekosistemlerle uyum içinde bulunmalıdır (Atıl ve ark., 2005). Su ve bitki örtüsünün zengin olduğu doğal ortamlar, bitki örtüsü bakımından fakir olan kent ortamlarına kıyasla çok daha rahatlatıcıdır (Schroeder, 1991). Kentlerde insanlar, rekreasyon aktiviteleri için doğal veya yapay yollarla oluşturulmuş su yüzeylerini ve yeşil alanları tercih etmektedirler. Suyun dinlendirici etkisi ve mikroklimatik özellikleri bu tercihte etkili olmaktadır. Ayrıca kentlerde bulunan bu tür rekreasyon alanları doğal, kültürel ve estetik değerlerin arttırılması ile kentin turistik açıdan daha çekici bir hale gelmesini sağlamaktadır. $\mathrm{Bu}$ suretle, gelir ve istihdam olanaklarının geliştirilmesinde de etkisi bulunmaktadır (Chiesura, 2004). Kentlerde yer alan su kıyıları; canlılar için yaşam ortamı oluşturmak, biyolojik çeşitliliği sağlamak, kıyı şeridi erozyon kontrolünü sağlamak, taşkın kontrolü yapmak, rüzgâr perdesi ve mikroklimatik ortam oluşturmak gibi etkilere sahiptir (Dugan, 1990; Kuşak, 2006). Su kıyıları ve su yüzeylerinin kıyısında yer alan bitkiler, kıyıları etkileyen dalga ve akıntı gibi kuvvetleri azaltmaktadır. Aynı zamanda, buradaki bitkiler kökleri ile tortu maddelerini depolayarak su yüzeylerinin kıyısındaki yerleşim ve tarım arazilerindeki erozyonu önlemektedir. Göl kıyıları yoğun yağışlar nedeniyle oluşan fazla suyu tutarlar. Yağışlarla toprak yüzeyinde biriken fazla su, su kıyılarında emilmekte ve yeraltı suyu olarak depolanmaktadır (Dean, 1978).

$\mathrm{Bu}$ çalışmada doğal veya yapay olarak oluşturulmuş göllerin çevresine yapılabilecek örnek bir tasarım gerekçeleriyle sunulmuştur. Türkiye'nin zengin coğrafyasında hemen her il ve ilçede yer alan birçoğu atıl veya yanlış kullanımlarla çevrelenmiş göl çevrelerine örnek bir öneri ile yerel yönetim ve bu konuda çalışma yapacaklara rehberlik etmesi öngörülmüştür.

\section{MATERYAL ve YÖNTEM}

\section{Materyal}

Çalışma alanı olarak belirlenmiş olan Sulugöl, Karadeniz Bölgesi'nin Orta Karadeniz Bölümü'nde yer alan Tokat ilinin Niksar ilçesine bağlı bir köydür. Şekil 1'de çalışma alanının ülke ve il içindeki konumu verilmiştir.

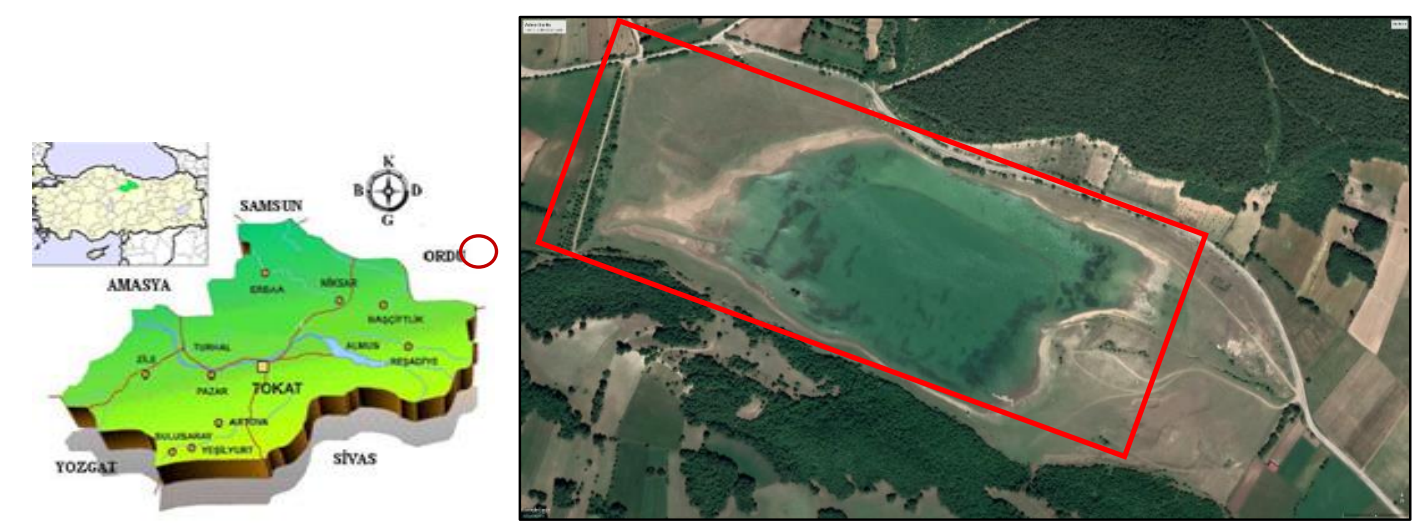

Şekil 1. Çalışma alanının ülke ve il içindeki konumu.

Figure 1. Location of the study area within the country and province. 
Niksar, 1861 yılında kurulmuştur. Yüzölçümü: 955 km2 olan kentin rakımı 350 m.'dir. Kentin, il merkezine uzaklığ 60 km.'dir. Niksar kentinin tarihi MÖ.64 yıllarına dayanmaktadır (Tokat Valiliği, 2019). Niksar'da Karadeniz iklimi ile İç Anadolu karasal iklimi arasında bir geçiş iklimi görülmektedir. Kışlar genellikle ılık ve yağışlı, yazlar ise sıcak geçer. Her ay yağış alan ilçenin yıllık yağış ortalaması 475,2 mm. iken yıllık sicaklık ortalaması $14,7^{\circ} \mathrm{C}$ 'dir (Ünal, 2004). Niksar ormanlarinda Quercus coccifera (Kermes meşesi), Fagus orientalis (Kayın) ve Pinus nigra (Karaçam) bitki türlerine rastlanmaktadır (Eliçalışkan, 2007). Niksar ekonomisi geniş ölçüde tarım ve orman ürünlerine dayalıdır (Niksar TSO, 2017). Türkiye İstatistik Kurumu (TÜİK)'na ait 2018 verilerine göre Niksar'ın nüfusu 65.308 kişidir. Nüfusun 49.66'sı erkek, \% 50.33'ü kadındır (TÜİK, 2020). Niksar, tektonik açıdan Türkiye'nin en aktif fay hatlarından Kuzey Anadolu Fay Hattı üzerinde yer almaktadır (Toprak ve Şahin, 2017). Bu nedenle, şehirde deprem riski hep gündemde olan bir konu olmuştur. Kent önemli depremler yaşamış ve birçok kez yıkılmıştır. Şekil 2'de çalışma alanı olan Sulugöl ve yakın çevresine ait fotoğraflar verilmiştir.

Sulugöl, Niksar kent merkezinden $7 \mathrm{~km}$. uzaklıkta bulunmaktadır. Köyün ekonomisi tarıma dayalıdır (IND, 2020). Çalışma alanında mevcut durumda herhangi bir rekreasyonel alan kullanımı yoktur.
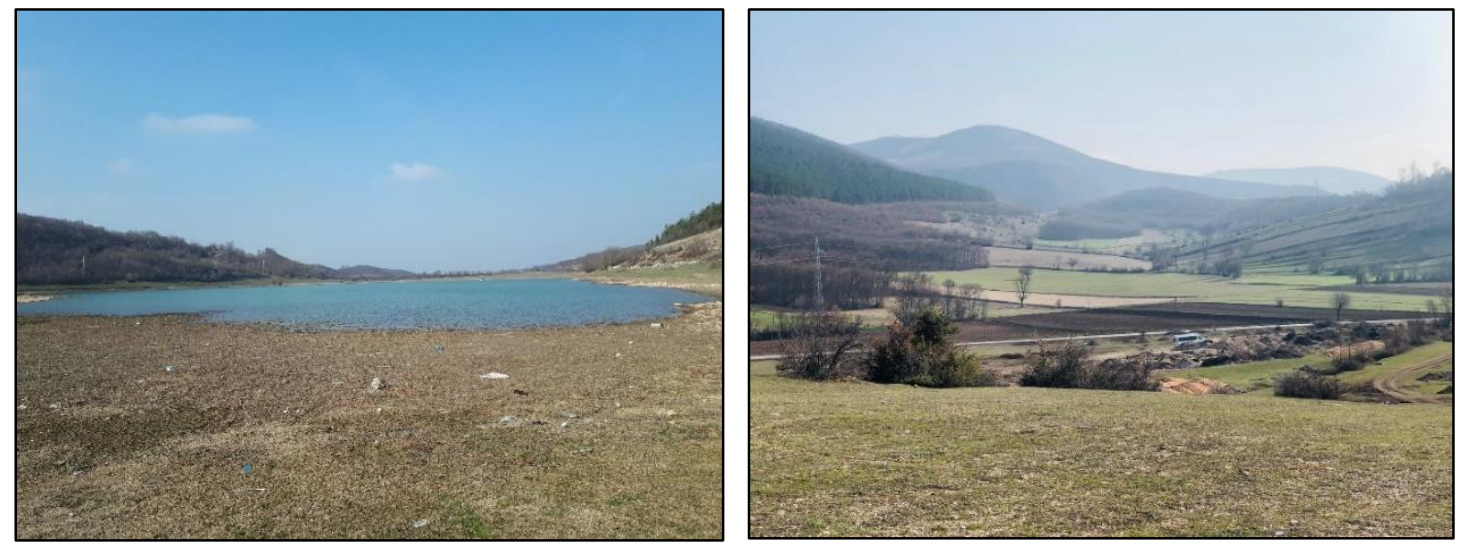

Şekil 2. Sulugöl ve yakın çevresinden görünümler.

Figure 2. Views from Sulugöl and its vicinity.

\section{Yöntem}

Çalışma veri toplama, analiz, değerlendirme ve sonuç olmak üzere 4 aşamada gerçekleştirilmiştir. Öncelikle alana ve konuya ilişkin literatür taraması yapılmıştır. Arazide yapılan çalışmalarda belediye yetkilileri ve halkla görüşmeler yapılarak kullanıcı istekleri ve beklentiler belirlenmiştir.

Şekil 3'te yapılan arazi çalışmalarından görünümler yer almaktadır. Arazi çalışması öncesinde yapılan literatür tarama ve arazide yapılan sörvey çalışması ile elde edilen veriler bilgisayar ortamında toparlanmış, yerel yönetimin karar vericileri ile sorun ve çözümler tartışılmış ve nihai plan kararlarına varılmıştır. Daha sonra, üretilecek peyzaj tasarım projesi için konsept ve konsepte göre tasarım ilkeleri belirlenmiştir. Konseptin seçiminde kentin tarihi yapısı ve alanın doğal özellikleri etkili olmuştur. Son aşamada ise; eskiz çalışmaları yapılarak alternatif tasarımlar oluşturulmuştur. Kesinlik kazanan proje çizgileri AutoCad 2017 programı kullanılarak bilgisayar ortamına aktarılmıştır. Projenin nihai hali, SketchUp ve Lumion yazılımıyla modellenmiş ve Photoshop CS5 programıla sunuma hazırlanmıştır.
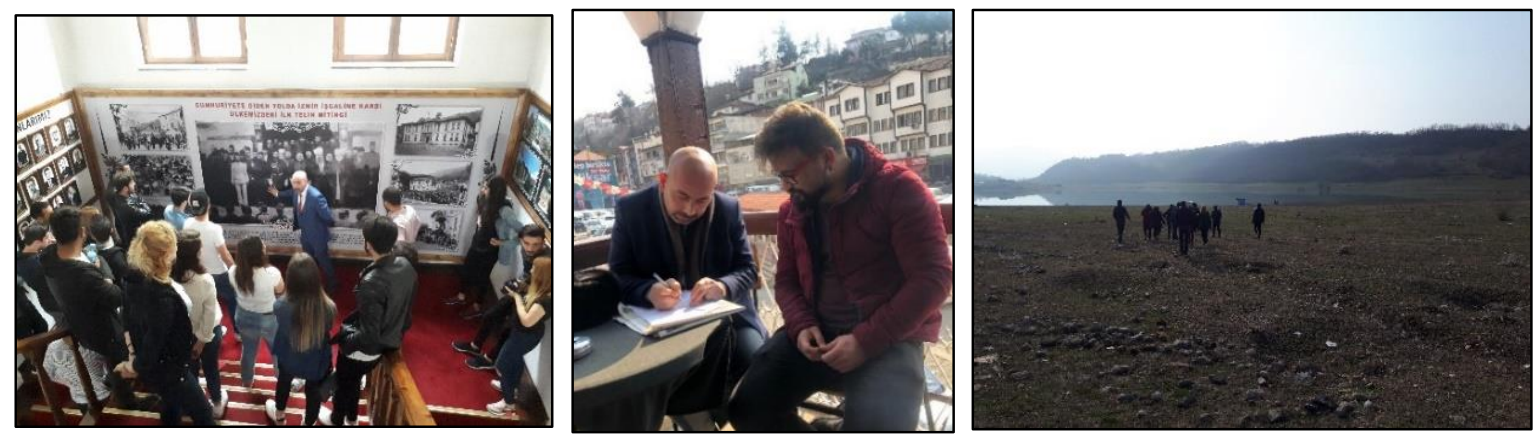

Şekil 3. Arazi çalışmalarından görünümler.

Figure 3. Views from the field studies. 


\section{BULGULAR}

$\mathrm{Bu}$ bölümde alan için geliştirilen peyzaj tasarım projesinin konsepti ve bu konsept dahilinde belirlenen alan kullanımlarına ilişkin bilgi verilmiştir.

Konsept: Projenin konsepti "Badem Çiçeği" olarak düşünülmüştür. Konseptin çıkış fikri "badem çiçeğinin baharı ve bahardaki renkliliği anımsatması"dır. Bu fikir ile projede tasarım aşamasında bahardaki renkliliği ifade edecek odak noktaları ve kullanım alanları tasarlanmıştır. Kullanım alanlarının belirlendiği Leke Plan aşamasına ait pafta Şekil 4'te verilmiştir.

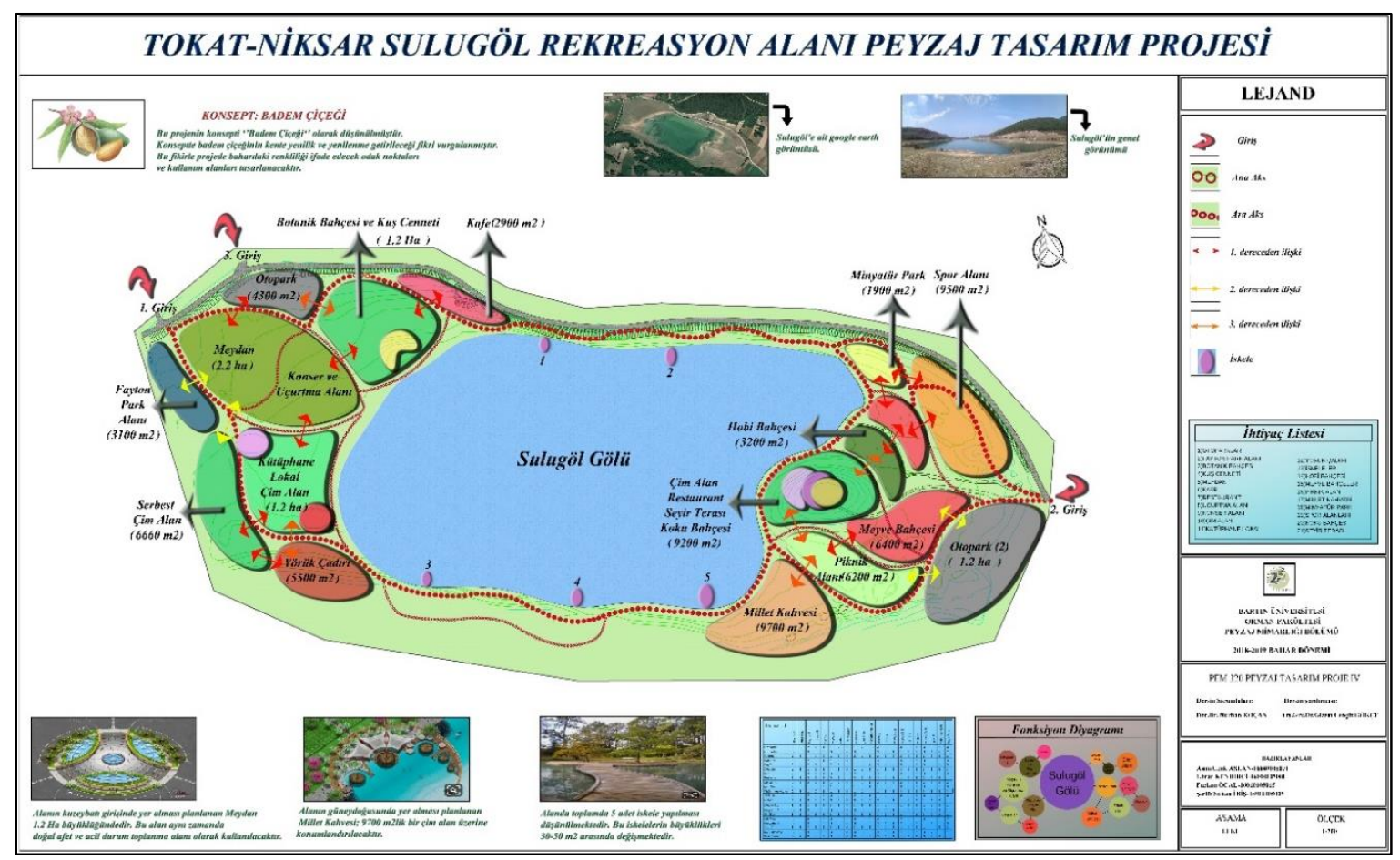

Şekil 4. Leke plan aşaması.

Figure 4. Stain plan phase.

Tasarım elemanları: Projede belirlenen alan kullanımları; otopark, fayton park alanı, bitki sergi alanı, kuş cenneti, meydan, kafe, restoran, uçurtma alanı, konser alanı, çim alanlar, kültür sanat evi (kütüphane ve lokal), Yörük çadırı, iskeleler, hobi bahçesi, meyve bahçeleri, piknik alanı, millet kahvesi, minyatür park, spor alanları ve seyir teraslarından oluşmaktadır. Kesin proje aşamasında oluşturulan pafta Şekil 5'te verilmiştir. Şekil 6-13'de ise yapılan peyzaj tasarımına ilişkin 3 boyutlu görünümler yer almaktadır.

Yaya ve araç ulaşımı: Çalışma alanına 1 adet kuzey yönlü, 1 adet kuzeybatı yönlü ve 2 adet doğu yönlü olmak üzere toplam 4 adet giriş planlanmıştır. Ana aksın giriş ile beraber genişliği $5 \mathrm{~m}$. olarak belirlenmiştir. Ana aks engelli yolunu ve fayton gezi yolunu da barındırmaktadır. Ana aks ve bağlantı yollarında prizma-küp taş döşeme kullanılmıştır. Tasarlanan yol güzergâhı ve seçilen döşeme malzemesi ile engellilerin alana erişebilmesi de sağlanmıştır. Ana aks ve bağlantılar ile alan içerisinde tüm noktalara eriş̧mek mümkündür. Bağlantı yolu olan ara aksın genişliği 2,5 m. olarak 4 kişinin aynı anda kullanımını sağlayacak şekilde oluşturulmuştur. Bisiklet yolu, gölün çevresini dolaşacak şekilde ana aksa paralel olarak tasarlanmıştır. Bisiklet yolu oluşturulurken 12.12.2019 tarih ve 30976 sayll resmî gazetede yayımlanan Bisiklet Yolları Yönetmeliği esas alınmış, yönetmelikte de belirtildiği gibi yol güzergâhı uzun ömürlü ve kaydırmaz özellikte mavi renk boya ile boyanmıştır. Bisiklet yolunun genişliği $2 \mathrm{~m}$. olarak planlanmıştır. Bisiklet yolu üzerinde 3 adet bisiklet park istasyonu konumlandırılmıştır. Bu durakların her birinin genişliği yaklaşık $20 \mathrm{~m}^{2}$ dir.

Minyatür park alanı: Alanın kuzeydoğusunda $1900 \mathrm{~m}^{2}$ büyüklüğe sahip olacak şekilde planlanmıştır. $\mathrm{Bu}$ alanda her yaş grubundan çocuğa hitap eden oyun elemanları, Niksar tarihi için önemli olan hükümdar karakterleri, kum havuzu, bitki labirenti, satranç alanı ve kafeye yer verilmiştir. Oyun alanı içerisinde ebeveynler için oturma alanı tasarlanmış olup gölge alanlar yaratılmıştır. Minyatür park alanının bitkisel tasarımında: Malus floribunda (Süs elmasi), Laurus nobilis (Defne), Platanus orientalis (Doğu çınarı), Pittosporum tobira (Yıldız çalısı), Viburnum opulus (Kartopu), Abelia grandiflora (Güzellik çalısı) bitkileri kullanılmıştır. Bitkilerin seçiminde kullanıcılar için gölgeli mekan oluşturma, bitkilerin yaprak rengi, çiçekleri ve kokularıyla görünümü zenginleş̧irmek amaçlanmıştır 


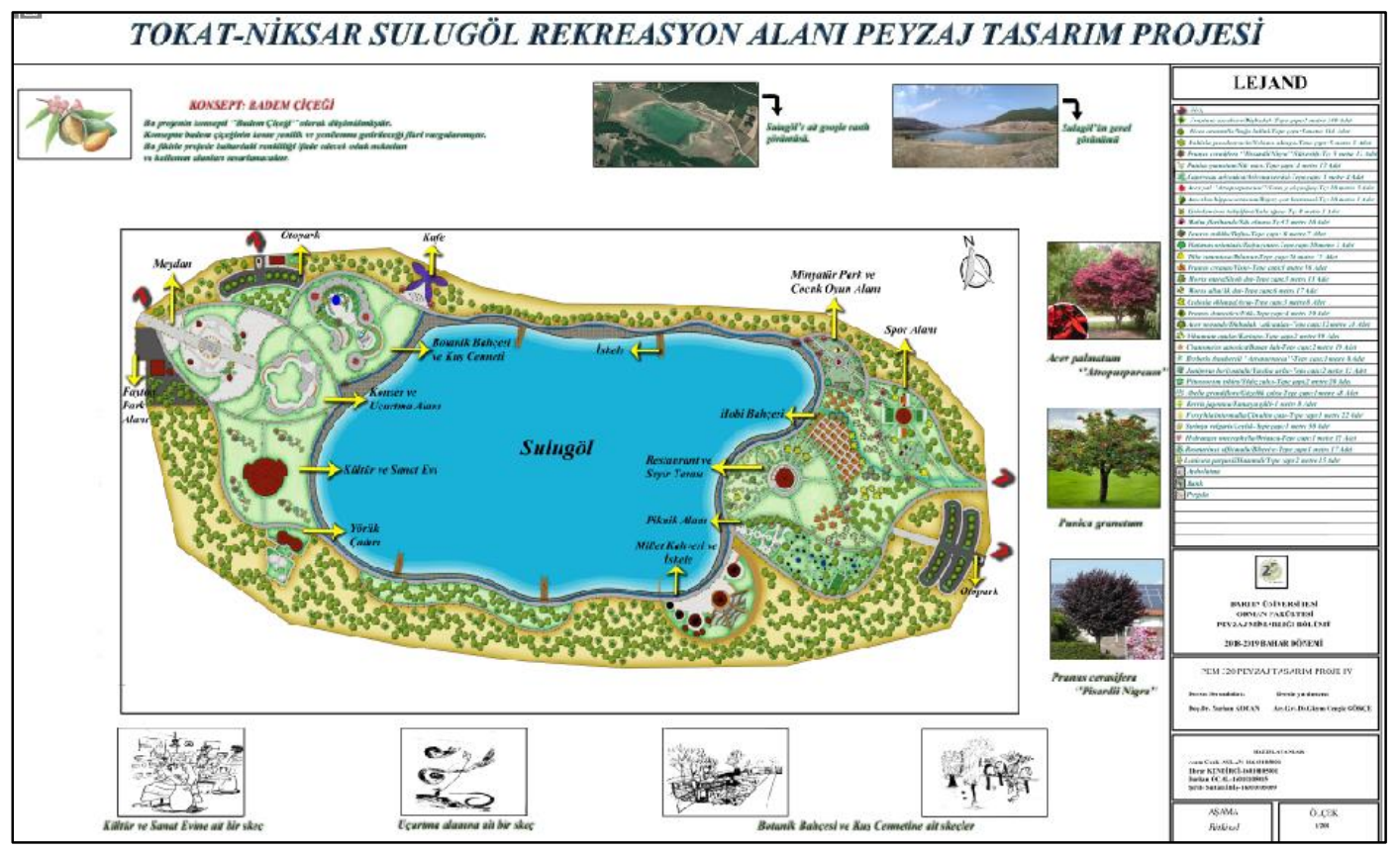

Şekil 5. Kesin proje aşaması.

Figure 5. Final project phase.

Piknik alanı: Alanın güneydoğu yönünde konumlandırılmıştır. Alanın büyüklüğü $6200 \mathrm{~m}^{2}$ olarak planlanmıştır. Piknik alanı içerisinde barbekü alanları bulunmaktadır. Kullanıcılar, kendi getirdikleri gidaları tüketilebildikleri gibi alan içerisinde bulunan büfeden de yiyecek-içecek temin edilebilmektedir. Alana, masa ve oturma birimlerinden oluşan üniteler yerleştirilmiştir. Alan içerisindeki oturma birimleri yarı açık olarak tasarlanmış olup alanda 4 adet süs havuzuna yer verilmiştir. Pikniğe gelen kişilerin kullanımına yönelik olarak 1 adet çok amaçlı spor sahası tasarlanmıştır. Ayrıca alanın kuzeybatı ve kuzeydoğu yönlerinde 2 adet wc konumlandırılmıştır. Piknik alanının bitkilendirilmesinde mevcutta yer alan Picea orientalis'den (Doğu ladini) yararlanılmıştır. Mevcuttaki ağaçların yeterli sayıda olması nedeniyle alana yeni ağaç eklenmemiştir. İğne yapraklı olan (Picea orientalis) ağaçlar arasında insanların piknik yapabileceği yeterli büyüklükte alan mevcut durumda korunmuştur..

Fayton park alanı: $3100 \mathrm{~m}^{2}$ büyüklügünde olup alanın kuzeybatısında bulunmaktadır. Her fayton için gerekli alan $30 \mathrm{~m}^{2}$ düşünülmüş olup aynı anda 8 fayton park edebilecektir. Faytonların bakım ve onarım atölyeleri de bu alan içerisinde yer alacaktır. Yine bu alan içerisinde fayton sürücüleri ve bakım־onarım görevlilerinin yemek, dinlenme vb. ihtiyaçlarını karşılamak adına 1 adet sekizgen köşeli kameriyeye yer verilmiştir. Alanda Fraxinus excelsior (Dişbudak) ve Picea orientalis (Doğu ladini) bitkileri kullanılmıştır. Picea orientalis mevcut durumda yer almaktadır. Fraxinus excelsior ise gölge amaçlı kullanılmıştır.
Otoparklar: Alanın kuzeyinde ve doğusunda olmak üzere 2 farklı noktada konumlandırılmıştır. Otopark alanları toplamda 136 otomobil ve 5 gezi otobüsü park edecek şekilde düşünülmüştür. Kuzeyde yer alan otoparkın içerisinde yönetim binası bulunmaktadır. Otoparklarda güvenli giriş-çıkış sağlanması adına güvenlik noktaları konumlandırılmıştır. Döşeme olarak asfalt tercih edilmiştir. Otopark bitkilendirme ilkelerine uygun olarak yapilan bitkilendirme tasarımında; Acer negundo (Akçaağaç) kullanılmıştır. $\mathrm{Bu}$ bitkinin seçim sebebi ise tepe çapının yüksek olması ve yapraklarının araçlara zarar vermeyecek formda olmasidir.

Kafe: Proje alanının tam merkezinde kafeye yer verilmiştir. Alanın büyüklüğü $2900 \quad \mathrm{~m}^{2}$ olarak planlanmıştır. Kafenin çatısı güneş panelleri kullanılarak tasarlanmıştır. $\mathrm{Bu}$ şekilde enerji tasarrufu sağlanacağı düşünülmektedir. Kafe alanı içinde açık ve kapalı oturma alanlarına yer verilmiştir. Alan Sulugöl'ün kuzeyinde bulunmaktadır. Kafe alanı, renkleri ve formuyla etkili olan Malus floribunda (Süs elması) ile vurgulanmıştır.

Restoran: Alanın kuzeydoğusundaki tepede konumlandırılmış olup eğim yönünde yukarıdan aşağıya doğru seyir terası ve koku bahçesi tasarlanmıştır. Seyir terası restoran ile doğrudan bağlantılı olup restoranın açık mekânı olarak da kullanılabilecektir. Bu üç kullanım için toplamda 9200 m2lik alan ayrılmıştır. Bu alanda kullanılan bitkiler; Forsythia intermedia (Çin altın çanı), Syringa vulgaris (Leylak), Rosmarinus officinalis (Biberiye), Abelia grandiflora (Güzellik çalısı), Lonicera purpusii (Hanımeli), Tilia tomentosa (Ihlamur), Prunus cerasus (Vişne), Punica granatum (Süs narı), Morus alba (Ak 
dut), Malus floribunda (Süs elması) ve Laurus nobilis (Defne)'dir. Restoran ve terasta oturan kullaniciların göl manzarasını seyrederken gözlemleyebilmesi amaciyla bu alanda renk etkisi olan bitkilere yer verilmiştir. Aynı zamanda ağaçların çiçek ve yaprak rengi ile koku vermesi seçimde etkili olmuştur.

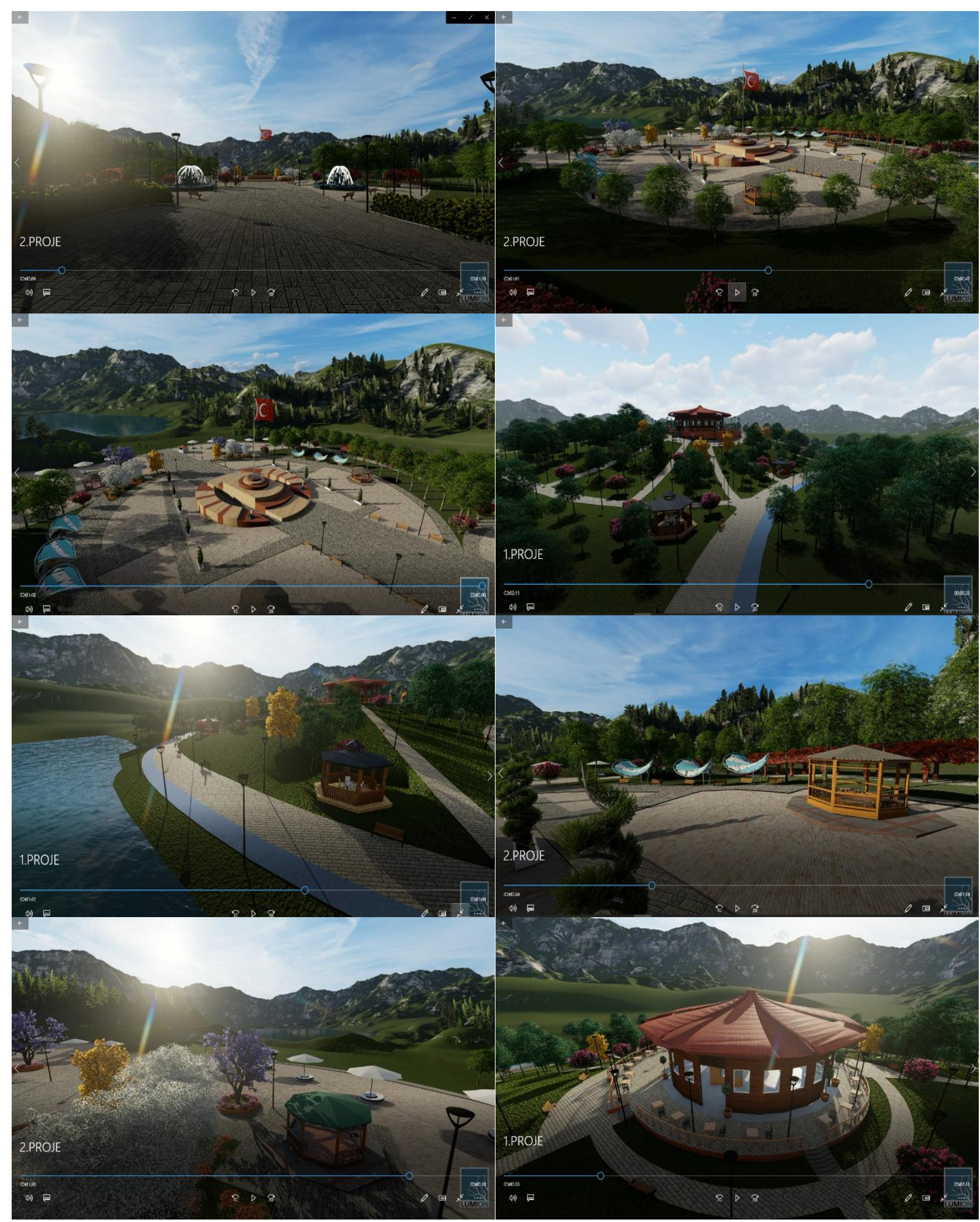

Şekil 6-13. Alan peyzaj tasarımının üç boyutlu (3D) görüntüleri

Figure 6-13. Three dimension (3D) views from landscape design of area

İskeleler: Sulugöl üzerinde toplam 5 adet iskele tasarlanmış olup bu iskelelerin büyüklükleri $30 \mathrm{~m}^{2}$ ile $50 \mathrm{~m}^{2}$ arasında değişmektedir. İskele etrafını saracak şekilde ahşap korkuluklara yer verilmiş olup olası kazalara karşı önlem alınmıştır.

Uçurtma alanı ve konser alanı: Alanın en ilginç noktalarından birini oluşturmaktadır. Bu alanda çocukların ve yetişkinlerin hareket ederken 
eğlenebilecekleri geniş bir yeşil alan tasarlanmıştır. Uçurtma aktivitesinin olmadığı zamanlarda bu alan toplanma ve konser alanı olarak hizmet verecektir. $\mathrm{Bu}$ alanın genişliği $10.000 \mathrm{~m}^{2}$ olarak planlanmıştır.

Spor alanları: Proje alanının kuzeydoğusunda yer verilmiştir. İçerisinde futbol sahası, basketbol sahası, voleybol sahası, tenis kortu ve fitness alanı bulunmaktadır. Kullanım alanlarının büyüklüğü hesaplandıktan sonra toplam alan büyüklüğü $9500 \mathrm{~m}^{2}$ olarak saptanmıştır. Spor alanlarının çevresinde gerek mahremiyetin sağlanması gerekse gürültünün önlenmesi amacıyla bitkisel perdeleme yapılmıştır. İzleyiciler için oturma basamaklarıyla tribün oluşturulmuştur. $\mathrm{Bu} 4$ spor kompleksinin tam merkezinde ve spor komplekslerine hâkim konumda bulunan bir açık oturma alanı tasarlanmıştır. Fitness alanı ise alanın güneyinde olup içerisinde her yaş grubunun kullanımına uygun elemanlara yer verilmiştir. Aynı zamanda fitness alanı içerisinde dinlenme imkânı sunan 2 adet kameriye konumlandirılmıştır. Spor alanlarının bitkilendirmesinde; Viburnum opulus (Kartopu), Pittosporum tobira (Yıldız çalısı), Syringa vulgaris (Leylak), Acer negundo (Dişbudak), Tilia tomentosa (Ihlamur) ve Malus floribunda (Süs elmasi) kullanılmıştır. Ağaçların çiçek ve yaprak rengi ile koku vermesi seçimde etkili olmuştur.

Hobi bahçeleri: Alanın kuzeydoğusunda yer almaktadır. Bu alan kentte bulunan okullarda eğitimöğretim gören öğrencilere ekim-dikim kültürü kazandırmak amacıyla tasarlanmıştır. Toplam 3200 $\mathrm{m}^{2}$ büyüklükte olması planlanmıştır. Alanların sınırlandırmaları bitkisel çitlerle yapılmıştır. Alanın iki sinırına komşu olacak şekilde toplam $9600 \mathrm{~m}^{2}$ büyüklüğündeki meyve bahçelerine yer verilmiştir. Hobi bahçeleri ve meyve bahçelerinde; Prunus cerasus (Vişne), Prunus cerasifera 'Pisardii nigra' (Süs eriği), Morus alba (Akdut), Malus floribunda (Süs elması), Punica granatum (Süs narl), Morus nigra (Siyah dut), Cydonia oblonga (Ayva) ve Prunus domestica (Erik) bitkileri kullanılmıştır. Insanların bitki ve meyve yetiştirme duygusunu pekiştirmek, meyvelerinden yararlanmak amacıyla bu türler seçilmiştir.

Yörük çadırı: Alanın güneybatısında $5500 \mathrm{~m}^{2}$ lik alan içerisinde konumlandırılmıştır. Yörük çadırının iç tasarımı Niksar tarihi geçmişine uygun olarak tasarlanmıştır. Osmanlı Devleti'nde kullanılan Yaren odaları geleneği bu çadırın içerisinde devam ettirilecektir. Aynı zamanda alanın çevresinde açık oturma alanlarına da yer verilmiştir. Yörük çadırının etrafinda geniş çim alan tasarlanmıştır.

Millet kahvesi: Alanın güneydoğusunda $9700 \mathrm{~m}^{2} \mathrm{lik}$ alan üzerine konumlandırılmıştır. $\mathrm{Bu}$ alanın içine Millet kahvesinin yanı sıra açı-kapalı oturma alanları, yöresel ürün satış alanı ve sergi alanı yerleştirilmiştir. Alandan iskeleye bağlanan geçiş estetik bir görünüm katmaktadır. Millet kahvesinin çevresinde sert zemin ve geniş çim alan tasarlanmıştır.

Kültür sanat evi (Kütüphane ve lokal): Alanın güneybatısında toplamda $12.000 \mathrm{~m}^{2}$ büyüklüğündeki alan üzerinde konumlandırılmıştır. Kütüphanede, kentteki öğrenciler için sakin bir çalışma ortamı yaratılmıştır. Çalışma zamanları dışında ise rekreasyon alanı içerisinde istedikleri sosyal aktiviteleri gerçekleştirebilme imkânı sunulmuştur. Binanın etrafında geniş çim alan üzerine pergola ve oturma elemanları konulmuştur. Alanın bitkilendirilmesinde; Prunus cerasifera 'Pisardii nigra' (Süs eriği), Cupressus arizonica (Arizona servisi), Viburnum opulus (Kartopu), Punica granatum (Süs narl) ve Hydrangea macrophylla (Ortanca) kullanılmıştır. Bitkilerin seçiminde yaprak rengi ve çiçekleriyle alana farklı renk katıp görünümü güzelleştirmeleri düşünülmüştür.

Meyve bahçeleri: Alanın doğusunda iki parça olarak $9600 \mathrm{~m}^{2}$ büyüklüğünde planlanmıştır. Bu alanda kullanıcıların, özellikle de çocukların meyve ağaçlarıyla etkileşim halinde olmaları amaçlanmıştır. $\mathrm{Bu}$ doğrultuda, yenilebilir peyzaja yönelik bir alan oluşturulmuştur.

Kuş cenneti: Alanın kuzeybatısında bitki sergi alanının içerisinde yer alıp $2000 \mathrm{~m}^{2}$ büyüklüğe sahiptir. Bu alanda yırtıcı kuşlar dışında kalan kuşlar (papağan vb.) sergilenecektir. Alanın tasarımı asmagerme sistemine benzer nitelikte dikmeler üzerine ağların gerilmesiyle sağlanacaktır. Bu büyük kafes içerisinde kuşların doğal ortamında bulunan bitkilere yer verilmiştir. Kuş cenneti etrafında; Acer palmatum 'Atropurpureum' (Kırmızı yapraklı akçaağaç), Forsythia intermedia (Çin altın çanı), Abelia grandiflora (Güzellik çalısı) ve Syringa vulgaris (Leylak) bitkileri kullanılmıştır. Bu alanda yine çiçek ve yaprak rengiyle ön plana çıkan bitki türleri tercih edilmiştir.

Meydan: Alanın kuzeybatı girişinin hemen önünde bulunup $12.000 \mathrm{~m}^{2}$ büyüklüktedir. $\mathrm{Bu}$ alan aynı zamanda doğal afet ve acil durum anında toplanma alanı olarak da kullanılacaktır. Alan içerisinde 16 Türk Devleti'nin bayrağı bulunmaktadır. Meydanın bitkilendirilmesinde, Robinia pseudoacacia (Yalanc1 akasya) ve Viburnum opulus (kartopu) kullanılmıştır. Türlerin seçiminde çiçek rengi ve koku vermesi etkili olmuştur.

Bitki sergi alanı: Alanın kuzeyinde yer alıp $10.000 \mathrm{~m}^{2}$ genişliğindedir. $\mathrm{Bu}$ alanda; tıbbi aromatik, egzotik ve endemik bitkilerden oluşan sistematik bir bitkisel tasarım uygulanmıştır. Böylece görsel etkinlik artırılmıştır. Alan ve çevresinde; Acer palmatum 'Atropurpureum' (Kırmızı yapraklı akçaağaç), Aesculus hippocastanum (Beyaz çiçekli atkestanesi), Liriodendron tulipifera (Lale ağacı), Prunus cerasifera 'Pisardii nigra' (Süs eriği), Robinia pseudoacacia (Yalancı akasya), Kerria japonica (Kanarya gülü), 
Juniperus horizontalis (Yayılıcı ardıç), Abelia grandiflora (Güzellik çalısı), Pittosporum tobira (Yıldız çalısı), Viburnum opulus (Kartopu), Berberis thunbergii 'Atropurpurea' (Adi kadintuzluğu) ve Chanomeles japonica (Bahar dalı) kullanılmıştır. Türlerin seçiminde yaprak rengi, çiçekli olması ve koku vermesi düşünülmüştür. Aynı zamanda yayılıcı

Çizelge 1. Proje alanında kullanılan bitkiler

Table 1. Plants used in the project area

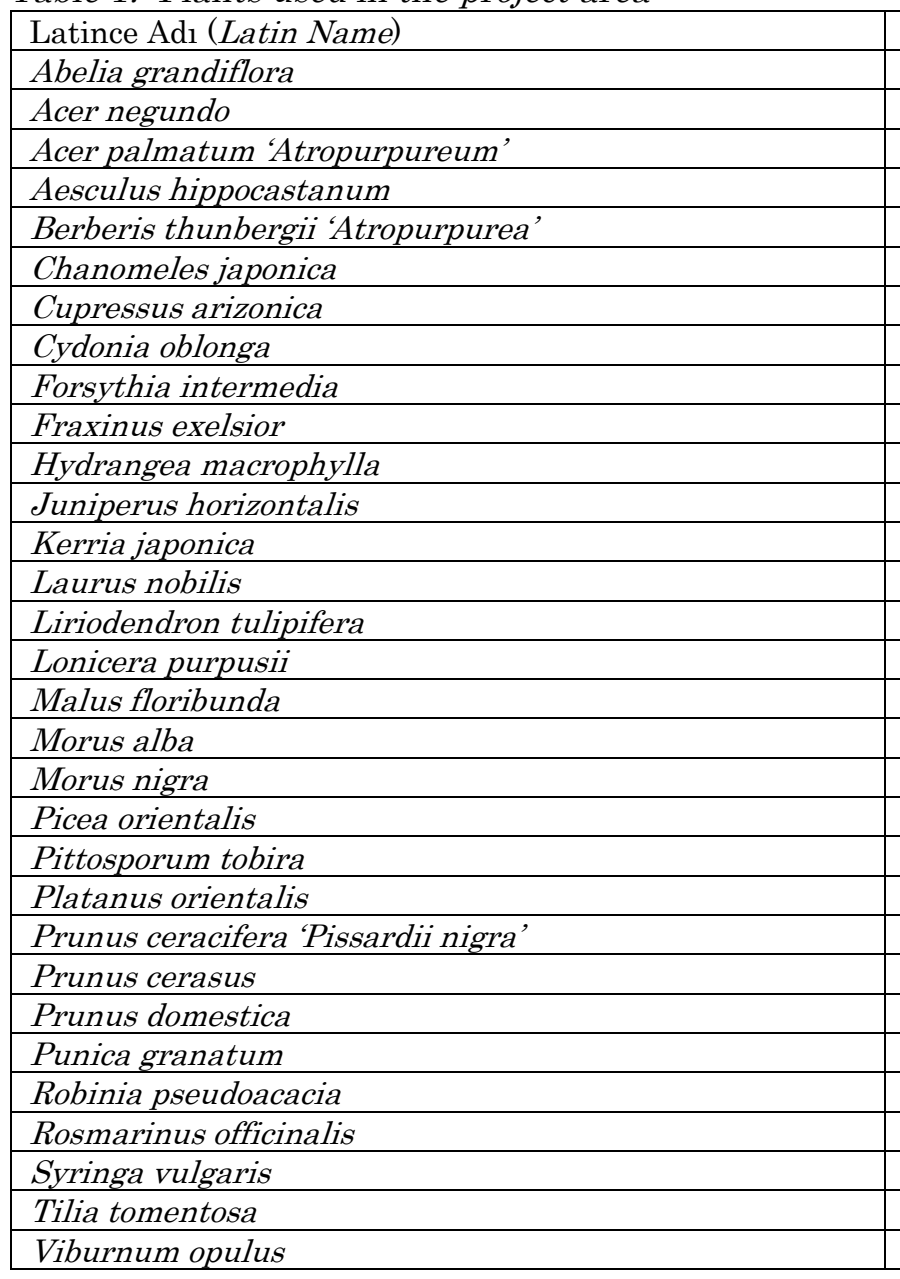

\section{SONUÇ}

Sulugöl Rekreasyon Alanı Peyzaj Tasarım Projesi’nde alan kullanımları, doğal çevrenin korunması ve bütüncül planlama anlayışıyla belirlenmiştir. Projede, alan potansiyellerinin sürdürülebilir kullanıma odaklanılmıştır.

Projenin uygulamaya geçirilmesi durumunda, kontrolsüz durumda iken çevresel ve sosyal yönden tehditlere açık olan alan sahip olduğu doğal ve kültürel özellikleriyle birlikte korunmuş olacaktır. Aynı zamanda kente alternatif bir rekreasyon alanı kazandırılacaktır. Koruma-kullanım anlayışına dayalı olarak doğal değerlerin korunmasına yönelik tasarımlar yapılmasıyla, Sulugöl ve çevresinin bugüne kadar yanlış ya da eksik kullanımına bağlı olarak gelişen tahribatların onarılması sağlanacaktır. Ekolojik denge gözeterek yapılan bitkisel tasarımlar türden çalı ve ağaca varan hiyerarşik düzende bitki boyutları da türlerin seçiminde etkili olmuştur.

Proje alanında uygulanan bitkisel tasarımda kullanılan bitki türleri Çizelge 1'de liste halinde verilmiştir.

\begin{tabular}{|l|l|}
\hline Türkçe Adı (Turkish Name) & Adet(Piece) \\
\hline Güzellik çalısı & 48 \\
\hline Dişbudak yapraklı akçaağaç & 24 \\
\hline Kırmızı yapraklı akçaağaç & 3 \\
\hline Beyaz çiçekli at kestanesi & 1 \\
\hline Adi kadıntuzluğu & 8 \\
\hline Bahar dalı & 10 \\
\hline Arizona servisi & 4 \\
\hline Ayva & 8 \\
\hline Çin altın çanı & 22 \\
\hline Dişbudak & 540 \\
\hline Ortanca & 12 \\
\hline Yayılıcı ardıç & 12 \\
\hline Kanarya gülü & 8 \\
\hline Defne & 7 \\
\hline Lale ağacı & 1 \\
\hline Hanımeli & 15 \\
\hline Süs elması & 10 \\
\hline Akdut & 17 \\
\hline Siyah dut & 11 \\
\hline Doğu ladini & 144 \\
\hline Yıldız çalısı & 20 \\
\hline Doğu çıarı & 2 \\
\hline Süs eriği & 12 \\
\hline Vişne & 16 \\
\hline Erik & 19 \\
\hline Süs narı & 12 \\
\hline Yalancı akasya & 3 \\
\hline Biberiye & 17 \\
\hline Leylak & 50 \\
\hline Ihlamur & 12 \\
\hline Kartopu & 59 \\
\hline & \\
\hline & 12 \\
\hline
\end{tabular}

ile biyoçeşitlilik arttırılarak diğer canlılar için de bir yaşam alanı oluş̧urulmuş olacaktır.

\section{Çıkar Çatışması Beyanı}

Makale yazarları aralarında herhangi bir çıkar çatışması olmadığını beyan ederler.

\section{Araștırmacıların Katkı Oranı Beyan Özeti}

Yazarlar makaleye eşit oranda katkı sağlamış olduklarını beyan ederler.

\section{TEŞEKKÜR}

Bartın Üniversitesi Orman Fakültesi Peyzaj Mimarlığı Bölümü 2018-2019 eğitim-öğretim yllı bahar yarıyılı PEM 320 Peyzaj Tasarımı Proje IV dersi kapsamında üretilen projenin arazi ve stüdyo 
çalışmalarında yardımcı olan Asım Cenk ASLAN, Ebrar KENDİRCI, Furkan ÖCAL ve Şerife Sultan İBİ̧̧’e teşekkür ederiz.

\section{KAYNAKLAR}

Atıl A, Gülgün B, Yörük İ 2005. Sürdürülebilir Kentler ve Peyzaj Mimarlığı, Ege Üniversitesi Ziraat Fakültesi Dergisi, 42 (2): 215-226.

Burmill S, Daniel TC, Hetherington JD 1999. Human Valuesand Perceptions of Water in AridLandscapes. Landscapeand Urban Planning, 44 (2-3): 99-109.

Çorbacı ÖL, Özyavuz M, Yazgan ME 2011. Peyzaj Mimarlığında Suyun Akıllı Kullanımı: Xeriscape, Tarım Bilimleri Araştırma Dergisi, 4 (1): 25-31.

Chiesura A 2004. The Role of Urban Parks for the Sustainable City. Landscape and Urban Planning, 68: 129-138.

Dean RG 1978. Effects of Vegetation on Shoreline Erosional Processes, Wetland Functions and Values: The State of Our Understanding. American Water Resources Association, 77 page.

Dugan PJ 1990. Sulak Alanların Korunması: Güncel Konular ve Gerekli Çalışmalar Üzerine Bir İnceleme. Doğal Hayatı Koruma Derneği, İstanbul, 96 sy.

Eliçalışkan M 2007. Tokat. Coğrafya Dünyası. http://www.cografya.gen.tr/. (Alınma Tarihi: 02.01. 2020).

Güney A, Hepcan Ş 1994. Akarsu-Göl Kıyılarında Erozyon ve Peyzaj Onarımı, Çevre Dergisi, 12: 4144.

Huang, SL 1998. A Study of People's Perception of Waterscapes in Built Environments. Doctor of Philosophy, Texas A \& M University, Texas.

IND 2020. İstanbul Niksarlılar Derneği, https://niksarder.com/niksar-sulugol-koyu/.

(Alınma Tarihi: 10.01.2020).

Kuşak B 2006. Su Kıyılarının Ekolojik Açıdan Değerlendirilmesi ve Restorasyonu. Yıldız Teknik Üniversitesi Fen Bilimleri Enstitüsü Şehir ve Bölge Planlama Anabilim Dalı, Yüksek Lisans Tezi, 180 sy

Niksar TSO 2017. 2017-2020 Stratejik Planı. Niksar Ticaret ve Sanayi Odası, Tokat, 47 sy.

Rees T, May P 2002. Su Bahçeleri Tasarım Kitabı [WaterGardens Design Book]. Yapı Endüstri Merkezi Yayınları, İstanbul, 144 sy.

Resmî Gazete 2019. Bisiklet Yolları Yönetmeliği. 12.12.2019 tarih ve 30976 sayll Resmî Gazete. https://www.resmigazete.gov.tr/eskiler/2019/12/201 91212-1.htm.

Schroeder HW 1991. Preferences and Meaning of Arboretum Landscapes: Combining Quantitative and Qualitative Data. J. Environ. Psychol. 11: 231248.

Şahin, N 2013. Kurakçıl Peyzaj Düzenlemesinde Suyun Etkin ve Akılcı Kullanımı-Xeriscape. Sitkı Koçman Üniversitesi Fen Bilimleri Enstitüsü Peyzaj Mimarlığı Ana Bilim Dalı, Yüksek Lisans Tezi, 75 sy.

Tokat Valiliği 2019. Tokat Valiliği İnternet Sitesi. http://www.tokat.gov.tr/tokatta-tarim-toprak-veturizm. (Alınma Tarihi: 12.01.2020).

Toprak Ö, Sahin H 2017. Niksar (Tokat) Yöresinin Jeodeğerleri. Türkiye Jeoloji Bülteni, 60 (1): 129143.

TÜIK 2020. Türkiye İstatistik Kurumu, Adrese Dayalı Nüfus Kaylt Sistemi 2019 Sonuçları. https://biruni.tuik.gov.tr/medas/?locale=tr.

Ünal Ç 2004. Şehir Coğrafyası Açısından Tokat. Aktif Yayınevi, Erzurum, 184 sf. 